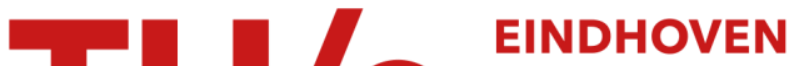 UNIVERSITY OF TECHNOLOGY
}

\section{Fast valuation and calibration of credit default swaps under Lévy dynamics}

Citation for published version (APA):

Fang, F., Jönsson, H., Oosterlee, C. W., \& Schoutens, W. (2009). Fast valuation and calibration of credit default swaps under Lévy dynamics. (Report Eurandom; Vol. 2009006). Eurandom.

Document status and date:

Published: 01/01/2009

\section{Document Version:}

Publisher's PDF, also known as Version of Record (includes final page, issue and volume numbers)

\section{Please check the document version of this publication:}

- A submitted manuscript is the version of the article upon submission and before peer-review. There can be important differences between the submitted version and the official published version of record. People interested in the research are advised to contact the author for the final version of the publication, or visit the $\mathrm{DOI}$ to the publisher's website.

- The final author version and the galley proof are versions of the publication after peer review.

- The final published version features the final layout of the paper including the volume, issue and page numbers.

Link to publication

\section{General rights}

Copyright and moral rights for the publications made accessible in the public portal are retained by the authors and/or other copyright owners and it is a condition of accessing publications that users recognise and abide by the legal requirements associated with these rights.

- Users may download and print one copy of any publication from the public portal for the purpose of private study or research.

- You may not further distribute the material or use it for any profit-making activity or commercial gain

- You may freely distribute the URL identifying the publication in the public portal.

If the publication is distributed under the terms of Article 25fa of the Dutch Copyright Act, indicated by the "Taverne" license above, please follow below link for the End User Agreement:

www.tue.nl/taverne

Take down policy

If you believe that this document breaches copyright please contact us at:

openaccess@tue.nl

providing details and we will investigate your claim. 


\title{
Fast Valuation and Calibration of Credit Default Swaps Under Lévy Dynamics
}

\author{
Fang Fang*, Henrik Jönsson ${ }^{\dagger}$, Cornelis W. Oosterlee ${ }^{\ddagger}$, and Wim Schoutens ${ }^{\S}$
}

February 18, 2009

${ }^{*}$ Delft University of Technology, Delft Institute of Applied Mathematics, Delft, the Netherlands, E-mail: f.fang@ewi.tudelft.nl

${ }^{\dagger}$ EURANDOM, Eindhoven University of Technology, Eindhoven, the Netherlands. E-mail: jonsson@eurandom.tue.nl,

${ }^{\ddagger}$ CWI - Centrum Wiskunde \& Informatica, Amsterdam, the Netherlands, E-mail: c.w.oosterlee@cwi.nl, and Delft University of Technology, Delft Institute of Applied Mathematics, Delft, the Netherlands

$\S$ Research Professor, K.U.Leuven, Department of Mathematics, Leuven, Belgium. E-mail: wim@schoutens.be 


\begin{abstract}
In this paper we address the issue of finding an efficient and flexible numerical approach for calculating survival/default probabilities and pricing Credit Default Swaps under advanced jump dynamics. We have chosen to use the firm's value approach, modeling the firm's value by an exponential Lévy model. For this approach the default event is defined as a first passage of a barrier and it is therefore possible to exploit a numerical technique developed to price barrier options under Lévy models to calculate the default probabilities. The method presented is based on the Fourier-cosine series expansion of the underlying model's density function.
\end{abstract}

Keywords: Lévy processes; Credit risk; Default probability; Credit Default Swaps; Fourier-cosine expansion JEL subject category: C02, C15, C63, G12 


\section{Introduction}

Credit default swaps (CDSs), the basic building block of the credit risk market, offer investors the opportunity to either buy or sell default protection on a reference entity. The protection buyer pays a premium periodically for the possibility to get compensation if there is a credit event on the reference entity until maturity or the default time, which ever is first. If there is a credit event the protection seller covers the losses by returning the par value. The premium payments are based on the CDS spread.

The spread of CDSs depends on the default probability of the underlying reference entity and it is possible to back out the market view of default probabilities for individual names from quoted market prices. It is therefore essential to be able to use advanced models in credit default modeling.

Lately Lévy models have attracted attention in the field of credit risk, see e.g. [5], [6] and [18]. [6] price CDSs using the structural approach with a Variance Gamma model driving the firm value. To calculate the default probabilities they derive the partial integro-differential equation (PIDE) satisfied by the barrier option price and solve the equation by adapting a numerical scheme developed by [11] for pricing American options. If the driving Lévy process in the firm value model only has negative jumps, i.e., it is a single-sided or spectrally negative Lévy process, then the default probabilities can be found by numerically performing a double Fourier inversion as shown in [18]. To price path dependent options on assets driven by jump diffusions with exponentially distributed Poissonian jumps with the use of fluctuation identities from the theory of Lévy processes has been worked out in [17] and [15, 16]. The resulting price formulas are of relatively simple explicit form when written as functions of the Laplace variable.

To price vanilla as well as exotic options on Credit Default Swaps can easily be set up in a structural model. In [12], the single-sided firm value models were used to generate dynamic CDS spreads by mapping the firm value paths to CDS spreads. In this way a Monte Carlo engine to price options on CDSs could be set up to price (exotic) options on CDSs. Having a method to generate dynamic CDS spreads available, it is also possible to value so called Constant Maturity CDSs, where the spread is reset periodically to the market spread of a CDS with constant maturity tenor, as described in [13].

We take a structural approach towards the modeling of credit risk, following the same methodology as [3], which defines the credit event to be the first time the value of the reference entity is below a predefined lower barrier representing the total debt of the firm. In contrast to [3], which used a Geometric Brownian motion to drive the firm value, we set up a firm value model driven by an exponential Lévy process. In particular, we study the model developed by [7] (CGMY), and the Normal Inverse Gaussian (NIG) processes.

We will show that default probabilities can be efficiently recovered from the Fourier-cosine series expansion of the underlying density, following the path of the COS method for European options in [9] and that for Bermudan options and discretely monitored barrier options in [10]. We can price a single CDS within fractions of a second and several CDSs in less than half a second with a high accuracy. Switching from one underlying model to another is furthermore as easy as switching from one characteristic function to another. This enables us to calibrate the Lévy models to market quotes of CDS prices easily and efficiently.

The paper is organized as follows. In Section 2 we present the mechanics and valuation of CDSs and introduce the Lévy firm value model. The COS method for survival probabilities is described in Section 3. A calibration study and some numerical examples are presented in Section 4. The paper ends with conclusions. 


\section{Lévy Default Model and Valuation of CDSs}

In this paper we follow the approach taken by [3] and model the default event of a firm as the first time the firm value crosses a low barrier.

Let us denote the risk neutral value of a firm at time $t$ as $V_{t}$, and assume that under an admissible pricing measure, $\mathbb{Q}$, it follows an exponential Lévy process, i.e.

$$
V_{t}=V_{0} \exp \left(X_{t}\right), \quad t \geq 0
$$

with $X_{t}$ being a Lévy process, which has independent and stationary increments and is stochastically continuous.

The Lévy processes of our particular interest here are the CGMY and the NIG processes.

The CGMY-process was introduced in [7] as a generalization of the famous Variance Gamma (VG) model. It is closely related to the KoBol process in [4]. The CGMY model has four parameters $C, G, M$ and $Y$, and the characteristic function reads

$$
\varphi_{C G M Y}(\omega, t)=\exp \left(t C \Gamma(-Y)\left[(M-i \omega)^{Y}-M^{Y}+(G+i \omega)^{Y}-G^{Y}\right]\right)
$$

with $C>0, G \geq 0, M \geq 0$, and $Y<2$. The parameter $C$ provides control over the kurtosis of the distribution; $G$ and $M$, respectively, control the rate of the exponential decay on the right and left of the Lévy density. Parameter $Y$ is particularly useful in controlling whether the process has finite or infinite activity. When $Y=0$, the model boils down to the VG process.

The Normal Inverse Gaussian (NIG) is a variance-mean mixture of a Gaussian distribution with an inverse Gaussian. The pure jump characteristic function of the NIG model reads

$$
\varphi_{N I G}(\omega, t)=\exp \left(t \delta\left(\sqrt{\alpha^{2}-\beta^{2}}-\sqrt{\alpha^{2}-(\beta+i \omega)^{2}}\right)\right),
$$

with $\alpha, \delta>0$ and $\beta \in(-\alpha, \alpha-1)$. The $\alpha$-parameter controls the steepness of the density in the sense that the steepness of the density increases monotonically with increasing $\alpha$. This has implications also for the tail behavior: large values of $\alpha$ imply light tails, while smaller values of $\alpha$ imply heavier tails. $\beta$ is a skewness parameter: $\beta>0$ implies a density skew to the right, $\beta<0$ a density skew to the left, and $\beta=0$ implies the density is symmetric around $0 . \delta$ is a scale parameter in the sense that the rescaled parameters $\alpha \rightarrow \alpha \delta$ and $\beta \rightarrow \beta \delta$ are invariant under location-scale changes of $x$ ([1]).

In the calibration study, we add a diffusion part to the NIG model and we denote this extended model NIG-BM. By doing this both the CGMY and the NIG-BM model are then having four parameters. More details on the diffusion part are discussed later on in the paper. As a result, the dynamics of NIG-BM model are driven by four parameters: $[\sigma, \alpha, \beta, \delta]$, where $\sigma$ is the volatility of the diffusion, and the characteristic function reads

$$
\varphi_{N I G-B M}(\omega, t)=\exp \left(t \delta\left(\sqrt{\alpha^{2}-\beta^{2}}-\sqrt{\alpha^{2}-(\beta+i \omega)^{2}}\right)-\frac{\sigma^{2} \omega^{2}}{2} t\right) .
$$

In what follows, we use $\varphi_{\text {levy }}$ to denote the characteristic functions of Lévy processes. 


\subsection{Lévy Default Model}

For a given recovery rate, $R$, default occurs the first time the firm's value is below the "reference value" $R V_{0}$. In particular, the time of default is defined as

$$
\tau_{d e f}:=\inf \left\{t \geq 0: V_{t} \leq R V_{0}\right\}
$$

If we focus on

$$
X_{s}=\ln \left(V_{s} / V_{0}\right) \text {, }
$$

then the risk-neutral survival probability in the time period $(0, t], \mathrm{P}_{\text {surv }}(t): \mathrm{P}_{\mathbb{Q}}\left(\tau_{\text {def }}>t\right)$, satisfies

$$
\begin{aligned}
\mathrm{P}_{\text {surv }}(t) & =\mathrm{P}_{\mathbb{Q}}\left(X_{s}>\ln R, \text { for all } 0 \leq s \leq t\right) \\
& =\mathrm{P}_{\mathbb{Q}}\left(\min _{0 \leq s \leq t} X_{s}>\ln R\right) \\
& =\mathbb{E}_{\mathbb{Q}}\left[\mathbf{1}\left(\min _{0 \leq s \leq t} X_{s}>\ln R\right)\right]
\end{aligned}
$$

where the indicator function $\mathbf{1}(A)$ equals 1 if the event $A$ is true and zero otherwise, and the subindex $\mathbb{Q}$ refers to the fact that we are working in a risk-neutral setting. Eq. (1) is nothing but the price of a Binary Down-and-Out Barrier (BDOB) option without discounting. This is a key observation that we will exploit in the remainder of this paper.

Different methods can be applied to find the default probabilities. For single-sided Lévy models, where the firm value only has negative jumps, the default probabilities can be calculated using the Wiener-Hopf factorization and a double Fourier inversion as shown in [18]. In case of VG, the default probabilities can be calculated by solving a PIDE as described in [6].

In this paper we use a recent efficient method to compute the survival probabilities and thus the CDS spreads under Lévy models. It is called the COS method and is based on the Fourier cosine-series expansion of the underlying density ([9]).

\subsection{Valuation of Credit Default Swaps}

Given a time period, say, $(0, \tau]$, we assume there are only a finite number of observing dates, $\mathcal{T}:=$ $\left\{\tau_{0}, \tau_{1}, \tau_{2}, \cdots, \tau_{M}\right\}$ with $\tau_{m}:=m \Delta \tau(m=0,1, \cdots, M)$ and $\Delta \tau:=\tau / M, \tau=\tau_{M}-\tau_{0}$, on which the firm value is monitored, such that

$$
\mathrm{P}_{\text {surv }}(\tau)=\mathbb{E}_{\mathbb{Q}}\left[\mathbf{1}\left(X_{\tau_{1}} \in[\ln R, \infty)\right) \cdot \mathbf{1}\left(X_{\tau_{2}} \in[\ln R, \infty)\right) \cdots \mathbf{1}\left(X_{\tau_{M}} \in[\ln R, \infty)\right)\right] .
$$

This coincides with the pricing formula for discrete digital options without discounting.

Let $f_{X_{\tau_{m+1}} \mid X_{\tau_{m}}}(\cdot \mid \cdot)$ denote the conditional probability density of $X_{\tau_{m+1}}$ given $X_{\tau_{m}}$ and define

$$
p\left(x, \tau_{M}\right):= \begin{cases}1, & x>\ln (R) \\ 0, & x \leq \ln (R)\end{cases}
$$


we then have the following recursive relation:

$$
\left\{\begin{aligned}
p\left(x, \tau_{m}\right) & :=\int_{\ln R}^{\infty} f_{X_{\tau_{m+1}} \mid X_{\tau_{m}}}(y \mid x) p\left(y, \tau_{m+1}\right) d y, \quad m=M-1, \cdots, 2,1,0 \\
\mathrm{P}_{\text {surv }}(\tau) & :=p\left(x=0, \tau_{0}\right)
\end{aligned}\right.
$$

where $p$ is the value of the virtual digital option without discounting.

This is the starting point of the numerical method derived in the next section.

Let us denote by $T$ the maturity of a CDS. The fair spread, $C$, of a CDS at the initialization date is the spread that equalizes the present value of the premium leg and the present value of the protection leg, i.e.

$$
C=\frac{(1-R)\left(\int_{0}^{T} \exp (-r(s) s) \mathrm{dP}_{d e f}(s)\right)}{\int_{0}^{T} \exp (-r(s) s) \mathrm{P}_{\text {surv }}(s) \mathrm{d} s}
$$

where $r(t)$ is the default-free discount rate over the time period $(0, t]$, and $\mathrm{P}_{\text {def }}(t)$ and $\mathrm{P}_{\text {surv }}(t)$ are the probability of default and the probability of survival, respectively, in the time period $(0, t]$. Note that in case of a default event the protection buyer is receiving $(1-R)$ for every insured currency unit, $R$ being the recovery. Eq. (4) indicates that the price of a CDS depends on the survival probability (and of course on the default probability) of the firm.

It is in principle possible to model a stochastic recovery rate, but in this paper we assume it to be constant.

When the interest rate is assumed to be constant in $[0, T],(4)$ can be simplified, via integration-by-parts, to

$$
C=(1-R)\left(\frac{1-e^{-r T} \mathrm{P}_{\text {surv }}(T)}{\int_{0}^{T} e^{-r s} \mathrm{P}_{\text {surv }}(s) \mathrm{d} s}-r\right),
$$

where $\mathrm{P}_{\text {surv }}(t)=1-\mathrm{P}_{\text {def }}(t)$ is used, see also $[6,18]$.

The price of a CDS is based on a series of survival probabilities on different time intervals. To see this, we discretize (5) using the composite trapezoidal rule, i.e.

$$
C_{\text {trap }}:=(1-R)\left(\frac{1-e^{-r T} \mathrm{P}_{\text {surv }}(T)}{\sum_{j=0}^{J} w_{j} e^{-r t_{j}} \mathrm{P}_{\text {surv }}\left(t_{j}\right) \Delta t}-r\right)=C+\epsilon_{c},
$$

where $\epsilon_{c}$ denotes the discretization error of the numerical integration rule (discussed later), and $w_{j}=\frac{1}{2}$ for $j=0$ and $j=J$ and $w_{j}=1$ otherwise. Eq. (6) suggests that a CDS price depends on a sequence of survival probabilities defined on the sequence of time intervals $\left(0, t_{0}\right],\left(0, t_{1}\right], \ldots,\left(0, t_{J}\right]$, with $t_{j}:=j \Delta t$ and $\Delta t:=T / J$. We will subsequently show that these survival probabilities can be approximated simultaneously in (almost) linear complexity.

\section{The COS Method}

In this section, we show how to compute the survival probabilities using the COS method from [10].

The Fourier-cosine series coefficients of the density $f_{X_{t} \mid X_{s}}(y \mid x)$, with $0 \leq s \leq t$, of a Lévy process are related to the characteristic function, as follows (see [9]):

$$
f_{X_{t} \mid X_{s}}(y \mid x)=\frac{2}{b-a} \sum_{n=0}^{\prime N-1} \operatorname{Re}\left\{\varphi_{\text {levy }}\left(\frac{n \pi}{b-a}, t-s\right) e^{i n \pi \frac{x-a}{b-a}}\right\} \cos \left(n \pi \frac{y-a}{b-a}\right)+\epsilon_{f},
$$


for $x, y \in[a, b] \subset \mathbb{R}$, and where $\sum^{\prime}$ denotes that the first term in the summation is halved. The error $\epsilon_{f}$ consists of the truncation errors related to the integration range and the series truncation. They have been discussed in [9], where it is stated that, when $[a, b]$ is sufficiently large, the series truncation error is dominating. Furthermore, the solution converges exponentially in $N$ for processes exhibiting smooth probability densities (in $\mathbb{C}^{\infty}[a, b]$ with nonzero derivatives), or, equivalently, for rapidly decaying characteristic functions. The interval $[a, b]$ is found to be sufficiently large with the following definition:

$$
[a, b]:=\left[c_{1}-L \sqrt{c_{2}+\sqrt{c_{4}}}, \quad c_{1}+L \sqrt{c_{2}+\sqrt{c_{4}}}\right] \quad \text { and } \quad L \in[7.5,10]
$$

where $c_{j}$ is the $j$ th cumulant of $X_{t}, f_{X_{t} \mid X_{s}}(y \mid x)$ with $x \in \mathbb{R} \backslash[a, b]$ is of the machine precision order. As such, with the above truncation interval and for a small $N$, Eq. (7) produces a highly accurate approximation of the underlying density $f_{X_{t} \mid X_{s}}(y \mid x)$.

\subsection{The COS Formula of Survival Probability}

With the same rule for the range of integration as in (8), Equation (3) can be rewritten as

$$
p\left(x, \tau_{m}\right)=\int_{\ln R}^{b} f_{X_{\tau_{m+1}} \mid X_{\tau_{m}}}(y \mid x) p\left(y, \tau_{m+1}\right) d y+\epsilon_{p}
$$

where error $\epsilon_{p}$, due to the size of the integration interval, is negligible (as $p\left(y, \tau_{m+1}\right)>0$ and $\int_{\mathbb{R}} p\left(y, \tau_{m+1}\right) d y=$ 1 , error $\epsilon_{p}$ is of the same order as $\left.\int_{x \in \mathbb{R} \backslash[a, b]} f_{X_{\tau_{m+1}} \mid X_{\tau_{m}}}(y \mid x) d y\right)$.

As a second step, we replace the conditional density in (9) by (7), so that

$$
p\left(x, \tau_{m}\right)=\sum_{n=0}^{\prime N-1} \phi_{n}(x) \cdot P_{n}\left(\tau_{m+1}\right)+\epsilon_{c o s},
$$

where $\epsilon_{p}$ is included in $\epsilon_{c o s}$, and for $m=0,1, \ldots, M-1$,

$$
P_{n}\left(\tau_{m+1}\right):=\frac{2}{b-a} \int_{\ln R}^{b} \cos \left(n \pi \frac{y-a}{b-a}\right) p\left(y, \tau_{m+1}\right) d y
$$

and

$$
\phi_{n}(x):=\operatorname{Re}\left\{\varphi_{\text {levy }}\left(\frac{n \pi}{b-a}, \Delta \tau\right) e^{i n \pi \frac{x-a}{b-a}}\right\} .
$$

Eq. (10) is in essence the COS formula for discrete barrier options (without discounting). By $\epsilon_{\cos }$ we denote the error in the COS formula, which is dominated by $\epsilon_{f}$ in (7).

Finally, the COS formula for the survival probability reads

$$
\left\{\begin{aligned}
\mathrm{P}_{\text {surv }}(\tau) & =p\left(x=0, \tau_{0}\right) . \\
p\left(x, \tau_{0}\right) & =\sum_{n=0}^{\prime N-1} \phi_{n}(x) \cdot P_{n}\left(\tau_{1}\right) .
\end{aligned}\right.
$$

Equation (13) suggests that, to get the survival probability, one only needs $\left\{P_{n}\left(\tau_{1}\right)\right\}_{n=0}^{N-1}$, the cosine coefficients of $p\left(x, \tau_{1}\right)$, which again only depend on $\left\{P_{n}\left(\tau_{2}\right)\right\}_{n=0}^{N-1}$ in Equations (10) and (11), and so forth.

In what follows, we will demonstrate that $\left\{P_{n}\left(\tau_{m}\right)\right\}_{n=0}^{N-1}$ can be recovered from $\left\{P_{n}\left(\tau_{m+1}\right)\right\}_{n=0}^{N-1}$ in almost linear computational complexity, and that $\left\{P_{n}\left(\tau_{1}\right)\right\}_{n=0}^{N-1}$ can therefore be recursively recovered from $\left\{P_{n}\left(\tau_{M}\right)\right\}_{n=0}^{N-1}$, the cosine coefficients of $p\left(x, \tau_{M}\right)=1, x>\ln (R), p\left(x, \tau_{M}\right)=0$ otherwise. 


\subsection{Backward Induction}

Starting from the definition of $P_{n}\left(\tau_{m}\right)$ in (11), we replace $p\left(y, \tau_{m}\right)$ by $(10)$ and insert (12) to obtain

$$
P_{n}\left(\tau_{m}\right)=\sum_{k=0}^{\prime N-1} \operatorname{Re}\left\{\varphi_{\text {levy }}\left(\frac{k \pi}{b-a}, \Delta \tau\right) \cdot \omega_{n, k}\right\} P_{k}\left(\tau_{m+1}\right)
$$

where $n=0,1, \cdots, N-1$, and

$$
\omega_{n, k}:=\frac{2}{b-a} \int_{\ln R}^{b} e^{i k \pi \frac{y-a}{b-a}} \cos \left(n \pi \frac{y-a}{b-a}\right) d y
$$

In form of matrix-vector-product, (14) becomes

$$
\mathbf{P}\left(\tau_{m}\right)=\operatorname{Re}\{\Omega \Lambda\} \mathbf{P}\left(\tau_{m+1}\right)
$$

where we use bold-faced letters to denote vectors, e.g. $\mathbf{P}\left(\tau_{m}\right)$ is the vector $\left(P_{0}\left(\tau_{m}\right), P_{1}\left(\tau_{m}\right), \ldots, P_{N-1}\left(\tau_{m}\right)\right)^{T}$. " $\Omega \Lambda$ " denotes a matrix-matrix multiplication with $\Omega$ being a matrix filled with $\left\{\omega_{n, k}\right\}_{n, k=0}^{N-1}$ and $\Lambda$ being a diagonal matrix filled by $\left\{\varphi_{\text {levy }}\left(\frac{k \pi}{b-a}, \Delta \tau\right)\right\}_{k=0}^{N-1}$. Applying (15) recursively, i.e. backwards in time, we obtain the induction formula for $\mathbf{P}\left(\tau_{1}\right)$ :

$$
\mathbf{P}\left(\tau_{1}\right)=(\operatorname{Re}\{\Omega \Lambda\})^{M-1} \mathbf{P}\left(\tau_{M}\right)
$$

with $\mathbf{P}\left(\tau_{M}\right)$ admitting an analytic solution since, for $n=0,1, \cdots, N-1$,

$$
P_{n}\left(\tau_{M}\right):=\frac{2}{b-a} \int_{\ln R}^{b} \cos \left(n \pi \frac{y-a}{b-a}\right) d y .
$$

Straight-forward computation of (16) is time-consuming. However, fortunately an efficient valuation technique exists.

From their definition, we know that the Fourier-cosine coefficients of real-valued functions are also realvalued, so that we can expand (16) into a recursive matrix-vector-product. For example, if there are 3 monitoring dates, we need to compute

$$
\mathbf{P}\left(\tau_{1}\right)=\operatorname{Re}\left\{\Omega\left[\Lambda \quad \operatorname{Re}\left\{\Omega\left[\Lambda \quad \operatorname{Re}\left\{\Omega\left[\Lambda \mathbf{P}\left(t_{3}\right)\right]\right\}\right]\right\}\right]\right\} .
$$

Note that " $\Lambda$ times vector $\mathbf{P}\left(t_{3}\right)$ " can be transformed into an element-wise multiplication of two vectors as $\Lambda$ is a diagonal matrix. Similarly, for $M$ monitoring dates, we have

$$
\mathbf{P}\left(\tau_{1}\right)=\operatorname{Re}\left\{\Omega\left[\Lambda \quad \cdots \quad \operatorname{Re}\left\{\Omega\left[\Lambda \quad \operatorname{Re}\left\{\Omega\left[\Lambda \mathbf{P}\left(t_{M}\right)\right]\right\}\right]\right\}\right]\right\}
$$

Furthermore, matrix $\Omega$ has a special structure, see [10]:

$$
\Omega=H+T,
$$


where

$$
H=\left[\begin{array}{ccccc}
w_{0} & w_{1} & w_{2} & \cdots & w_{N-1} \\
w_{1} & w_{2} & \cdots & \cdots & w_{N} \\
\vdots & & & & \vdots \\
w_{N-2} & w_{N-1} & \cdots & & w_{2 N-3} \\
w_{N-1} & \cdots & & w_{2 N-3} & w_{2 N-2}
\end{array}\right]_{N \times N}
$$

is a Hankel matrix, and $T$ is a Toeplitz matrix:

$$
T=\left[\begin{array}{ccccc}
w_{0} & w_{1} & \cdots & w_{N-2} & w_{N-1} \\
w_{-1} & w_{0} & w_{1} & \cdots & w_{N-2} \\
\vdots & & \ddots & & \vdots \\
w_{2-N} & \cdots & w_{-1} & w_{0} & w_{1} \\
w_{1-N} & w_{2-N} & \cdots & w_{-1} & w_{0}
\end{array}\right]_{N \times N}
$$

with

$$
w_{j}:= \begin{cases}\frac{\left(x_{2}-x_{1}\right)}{b-a} & j=0, \\ -\frac{i}{\pi} \cdot \frac{\exp \left(i j \frac{\left(x_{2}-a\right) \pi}{b-a}\right)-\exp \left(i j \frac{\left(x_{1}-a\right) \pi}{b-a}\right)}{j} & j \neq 0 .\end{cases}
$$

It is well-known that matrix-vector products with the matrix being either a Hankel or a Toeplitz matrix can be transformed into a circular convolution of two vectors. Therefore, the FFT algorithm can be applied, and thus the recursive matrix-vector products in $(17)$ can be computed in $(M-1) N \log _{2}(N)$ operations.

Remark 3.1. Computational effort can be saved further if we compute several survival probabilities simultaneously, in one computation. For example, suppose that we have two time intervals $\left(0, t_{1}\right] \subset\left(0, t_{2}\right]$. We can then define the time partitioning on $\left(0, t_{2}\right]$ in such a way that $t_{1}$ is exactly on the grid, e.g., $t_{1}=\lambda t_{2} / M$ with $\lambda$ being a positive integer less than $M$. We now find that

$$
\mathbf{P}\left(\tau_{1} ; t_{1}\right) \equiv \mathbf{P}\left(\tau_{M-\lambda+1} ; t_{2}\right)
$$

Thus, the Fourier-cosine coefficients of the survival probability on $\left(0, t_{1}\right]$ can be recovered at no cost during the computation of $\mathrm{P}_{\text {surv }}\left(t_{2}\right)$.

\section{Choice of Parameters and Error Analysis}

To use (13) for CDS spreads, we need to determine three relevant parameters: $N$, the number of terms of the cosine series expansion; $M$, the number of monitoring dates and $J$, the number of quadrature points to discretize the integrals in (4). These parameter values are based on the following insights.

\subsection{Local Error Convergence}

The choice of $N$ is comparatively simple, as $N$ is only related to the error convergence of the COS reconstruction of the underlying probability density, which is directly related to the convergence rate of its Fourier-cosine series expansion. One can find a detailed error analysis of $\epsilon_{\cos }$ in (10) from [9] and for the error propagation in the recursive induction in [10]. 
For example, as Figure 1 suggests, the convergence speed of the absolute errors is exponential, and with $N=2^{10}$ the errors are substantially smaller than 1 basis point.

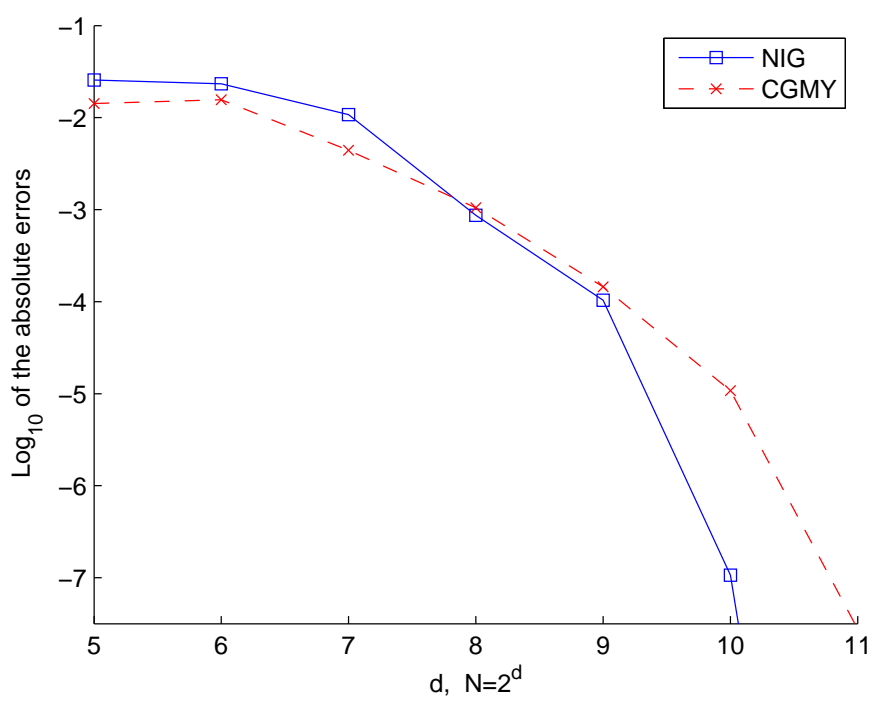

Figure 1: Convergence of $\mathrm{P}_{\text {surv }}(\Delta \tau=1 / 48)$ w.r.t. the number of terms in the cosine series expansion $(N)$ for NIG-BM and CGMY; Parameters are given in Table 1.

\subsection{Number of Monitoring Dates and Integration Points}

From a practical point of view, all CDSs should be monitored daily, i.e. the mesh size in time, $\Delta \tau$, has to be $1 / 252$ years if there are 252 working days per year. This is equivalent to setting $M=2520$ for a CDS which matures in 10 years. Such values for $M$ make the overall computation expensive for calibration purposes.

However, one can employ larger values of $\Delta \tau$ at the cost of some accuracy. In [14] the convergence of the price of discrete barrier options with $m$ monitoring dates to the price of the equivalent continuous barrier option was presented within the Black-Scholes model. A similar proof of convergence under Lévy processes is not available, however, via various numerical experiments under these processes, we have observed a regular convergence pattern in the prices of discrete barrier options w.r.t. the number of monitoring dates. We observed that the survival probabilities computed with a coarser time step converge to that with $\Delta \tau=1 / 252$.

Experiments give some evidence that this convergence is found for extreme parameter settings as well. An example can be found in the Series 8 iTraxx quotes for any component company (during the credit crunch of early 2008). In Table 1 the calibrated parameters for "ABN AMRO" on date 2-20-2008 under NIG-BM and CGMY are given.

Table 1: Calibrated parameters for "ABN AMRO Bank" on date 2-20-2008

\begin{tabular}{|c|c|c|c|c|c|}
\hline Model & $R$ & $T$ & $r$ & $\sigma$ & Other Parameters \\
\hline NIG-BM & 0.4 & 1 & 0.04 & 0.206 & $\alpha=3.043, \quad \beta=-2.38, \quad \delta=0.044$ \\
CGMY & 0.4 & 1 & 0.04 & 0 & $C=0.038, \quad G=0.60, \quad M=11.10, \quad Y=1.32$ \\
\hline
\end{tabular}




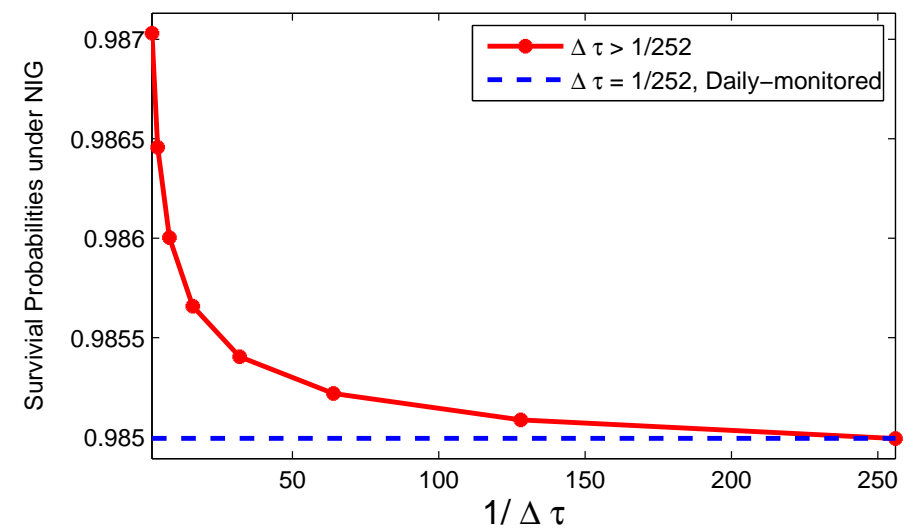

(a) NIG-BM

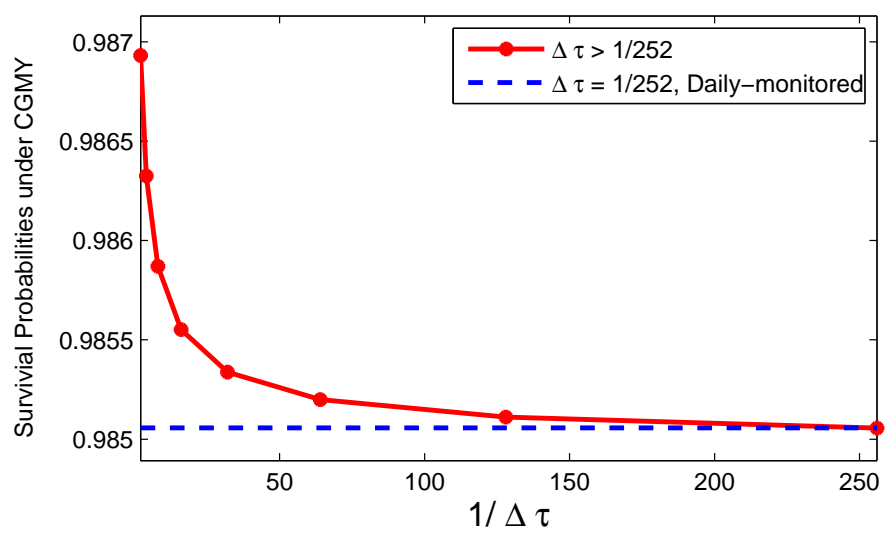

(b) CGMY

Figure 2: Convergence of the 1-year survival probability w.r.t. $\Delta \tau$ with parameters given in Table 1.

The convergence of the survival probabilities for the example in Table 1 is displayed in Figure 2. One can see that the difference between the weekly-monitored survival probabilities $(\Delta \tau=1 / 48)$ and the dailymonitored versions $(\Delta \tau=1 / 252)$ is at most 2 basis points. This difference is smaller when the parameter values are less extreme. Therefore, we use $\Delta \tau=1 / 48$, or $M=48 T$, in the calibration to follow.

To get an idea on how fast $\mathrm{P}_{\text {surv }}$ converges w.r.t. $M$, we need to examine the structure of the matrices $\Omega$ and $\Lambda$ in (17). According to its definition, $\Omega$ is a constant matrix that does not depend on the underlying model, nor on its parameters, whereas the diagonal matrix $\Lambda$ does. The elements on the diagonal of $\Lambda$ are defined as $\varphi_{\text {levy }}(k \pi /(b-a), \Delta \tau)$, so that the convergence rate of $\mathrm{P}_{\text {surv }}$ w.r.t. $M$ solely depends on how fast the characteristic function decays.

For the number of points used in the trapezoidal rule $(J)$ in $(6)$, we find that the computed CDS spreads are not very sensitive to the size of $J$. Therefore, we use, in the calibration to follow, $J=M / 4$, which gives only small differences (less than 0.1 basis point as shown in Figures 3 and 4 ) to the results computed with $J=M$ integration points. The second order convergence of the trapezoidal rule is confirmed in the righthand side pictures of the Figures 3 and 4. 


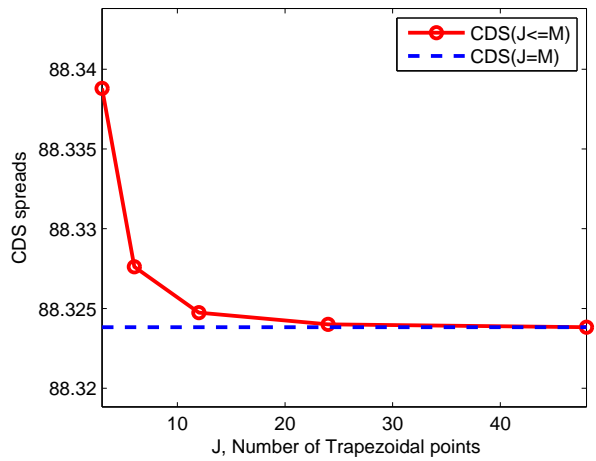

(a) Convergence of CDS spreads w.r.t. $J$

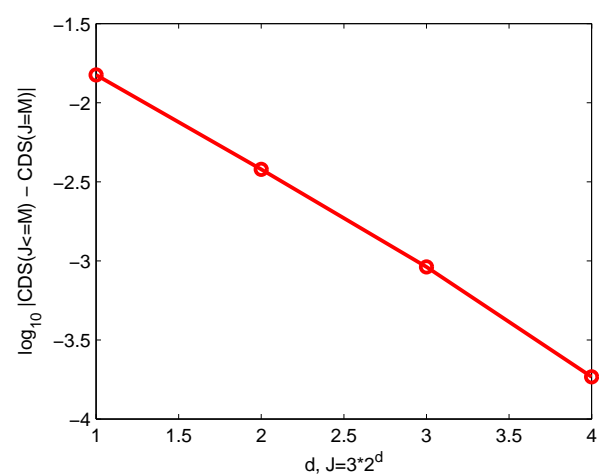

(b) Second order convergence of the trapezoidal rule

Figure 3: Convergence of the CDS spreads w.r.t. the number of points used in the trapezoidal rule $(J)$ under NIG, with parameters given in Table 1 .

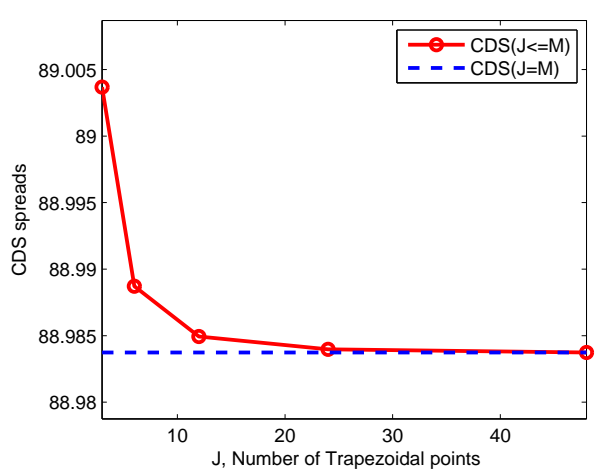

(a) Convergence of CDS spreads w.r.t. $J$

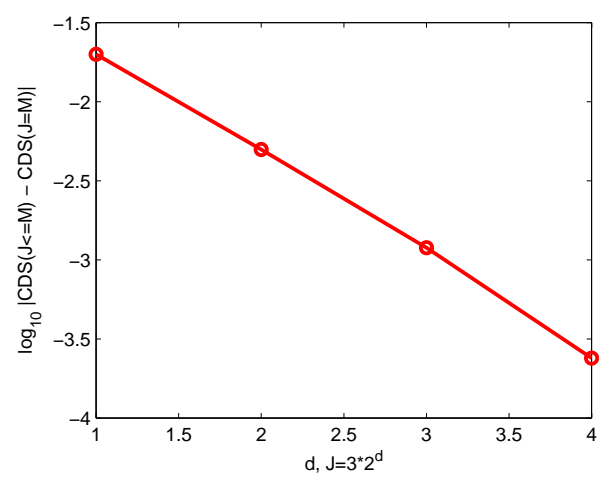

(b) Second order convergence of the trapezoidal rule

Figure 4: Convergence of the CDS spreads w.r.t. the number of points used in the trapezoidal rule $(J)$ under CGMY, with parameters given in Table 1.

\section{Calibration}

We investigate the performance of the proposed numerical scheme to calculate the CDS spreads by calibrating the NIG-BM and the CGMY models to a set of CDS prices.

\subsection{Calibration Setting}

The data sets are the weekly quotes from iTraxx Series 7 (S7) and 8 (S8). We have chosen to calibrate the models to spreads for CDSs with maturity 1, 3, 5, 7, and 10 years. This study makes use of 106 firms that are common to both series.

As the risk-free discount rate we have used the averaged EURIBOR swap rates.

We deal with the well-known ill-posedness of the inverse problem in the calibration framework (see, for example, [8]) by defining the objective function to be the root mean square error (RMSE) plus a regularization term, i.e.

$$
F_{o b j}=\mathrm{RMSE}+\gamma \cdot\left\|\mathbf{X}_{2}-\mathbf{X}_{1}\right\|_{2},
$$


where

$$
\text { RMSE }=\sqrt{\sum_{\text {CDS }} \frac{(\text { market CDS spread }- \text { model CDS spread })^{2}}{\text { number of CDSs on each day }}},
$$

$\|\cdot\|_{2}$ denotes the $L_{2}-$ norm, and $\mathbf{X}_{2}$ and $\mathbf{X}_{1}$ are the parameter vectors of two data sets. This kind of objective function also gives parameter consistency over time.

By the weighting factor $\gamma$, the regularization term influences the difference between two measures on two consecutive dates. This parameter can also be defined as a vector of the same length as $\mathbf{X}_{2}$ and $\mathbf{X}_{1}$, if the sensitivities of the CDS values to the component parameters differ significantly in magnitude. In that case, "." denotes the inner product of two vectors. With the objective function above, we aim to define a satisfactory measure, which fits the market data well and is - more or less - time-invariant.

Note that the choice of $\gamma$ in the objective function has a significant impact on the quality of the calibration fit. If the weighting on the regularization term is too high, the RMSE increases; If the weighting is too small, the parameter values are not stable over time. We use $\gamma=[2,0.5,0.5,0.5]$ for the NIG-BM model, corresponding to the set $[\sigma, \alpha, \beta, \delta]$. More weight is then assigned to $\sigma$ because the initial calibration revealed that the CDSs are more sensitive to $\sigma$ than to the other three parameters. As for the CGMY models, we employ $\gamma=[2,0.5,0.5,2]$ corresponding to the set $[C, G, M, Y]$. More weighting is assigned to $C$ and $Y$ because with these two one has a significant influence on the shape of the densities, compared to $G$ and $M$.

\subsection{Calibration Results}

Our first observation is that both the NIG-BM and the CGMY models give rise to a very good fit to the market data. A summary of the RMSE results for all the 106 companies that are present in both S7 and S8 of iTraxx is presented in Table 2.

Table 2: Summary of calibration results (in basis points) of all 106 firms in iTraxx

\begin{tabular}{|c|c|c|c|c|}
\hline RMSE & NIG-BM in S7 & CGMY in S7 & NIG-BM in S8 & CGMY in S8 \\
\hline Average (bp.) & 0.89 & 0.79 & 1.65 & 1.54 \\
Min. (bp.) & 0.22 & 0.29 & 0.27 & 0.46 \\
Max. (bp.) & 2.29 & 1.97 & 4.27 & 3.52 \\
\hline
\end{tabular}

From this we can see that the RMSE of both Lévy models for the Series 7 data are less than 1.0 basis point, and from those for the Series 8 they are less than 2.0 basis points. Detailed information about the RMSE for each individual company is summarized in the tables in Appendix A.

Because the S7 and S8 CDS spreads data starts from March 2007 and ends at March 2008, i.e., including part of the credit crunch period, the CDS spreads all increase in time. Furthermore, the strong fluctuations in the CDS curves are an indication for the increasing volatility in the credit market.

A typical example from our calibration results is given in Figure 5, where we plotted the NIG-BM and CGMY results for ABN AMRO CDS spreads. Note that nearly $80 \%$ of all the companies have a very similar CDS evolution. The highly satisfactory match of the computed CDSs to the market CDSs of both Lévy models can be seen.

Even in the extreme case, where the CDS spreads have very high values, the data are still fitted very well, see for example Figure 6, where the NIG-BM and the CGMY model fit the DSG International PLC CDS spreads, even though the CDSs went to nearly 500 basis points. 


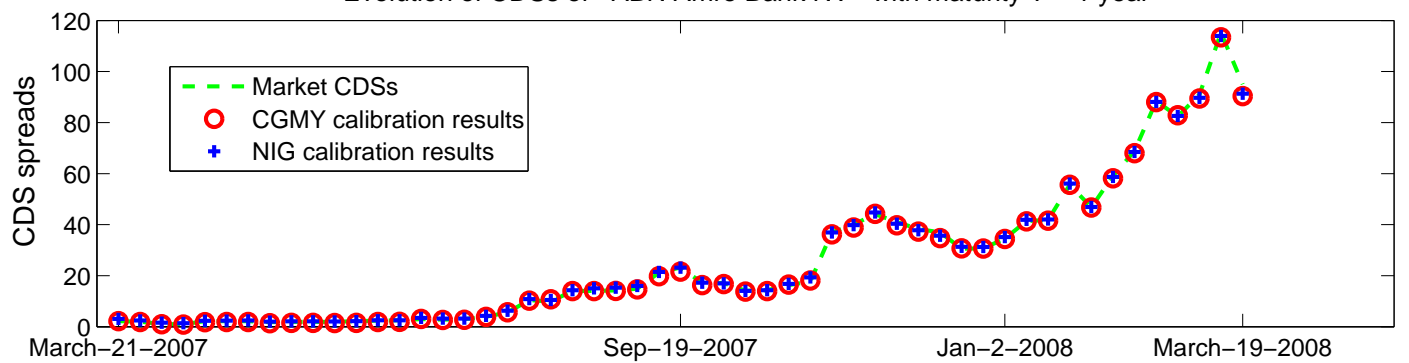

Evolution of CDSs of ABN Amro Bank NV with maturity $T=5$ year

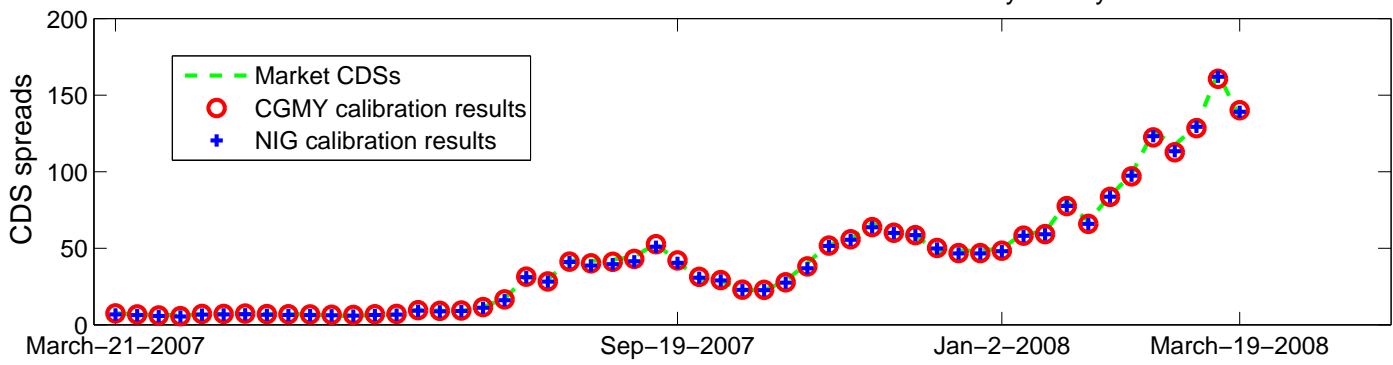

Evolution of CDSs of ABN Amro Bank NV with maturity $T=10$ year

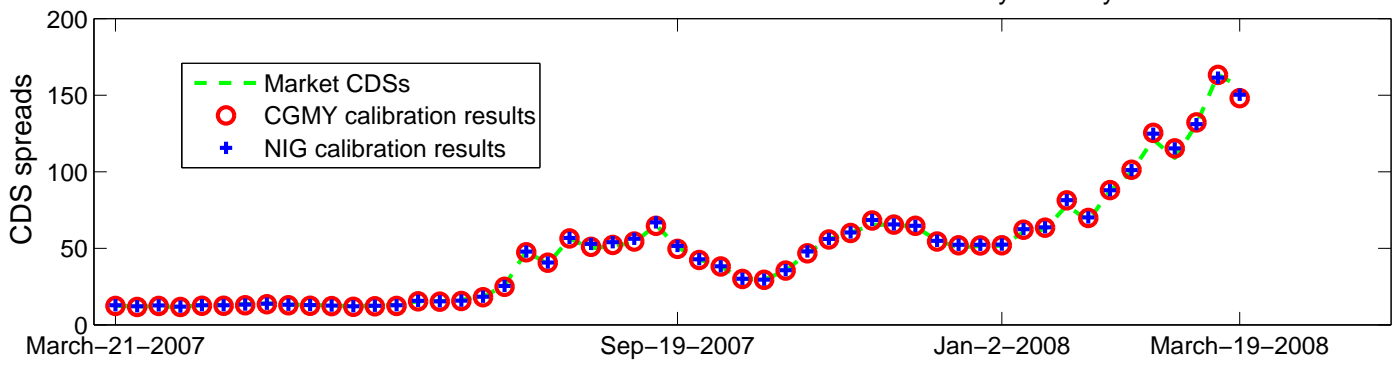

Figure 5: Calibration fit to ABN AMRO Bank CDS spreads for the CGMY and the NIG-BM models. Market CDS spreads '- -', CGMY CDS spreads 'o', and NIG-BM CDS spreads '+'.

In Figure 7, the evolution of the parameters of the CGMY and NIG-BM densities for ABN AMRO are plotted. We note the parameters are in reasonable range and that they evolve quite "smooth" over time. The jump in the parameters around September 19, 2007, reflects the jump in the CDS spreads in this period (cf. Figure 5). Recall from Table 2 that the average RMSE results for both models are small. It is also worth noting that the value of the $\sigma$ parameter in the NIG-BM model is in the range of 0.1 to 0.2 , indicating that the Brownian Motion contributes to the overall behavior of the model. In Figure 8, the evolution of the NIG-BM density is given. Here we can see that the density is more peaked in the beginning of Series 7 and then flattens out in the end of Series 8.

The CPU times for computing 1-, 3-, 5-, 7- and 10-year CDSs are summarized in Table 3. The calibration routine was implemented in MATLABß and the computer used for the calibration has an Intel® Core(TM)2 Duo CPU @ 2.20GHz, with $2048 \mathrm{~KB}$ Cache. In less than 0.5 seconds, the 5 CDSs for one company are computed, independent of the specific type of the underlying process. Although we use $N=2^{11}$ in the 

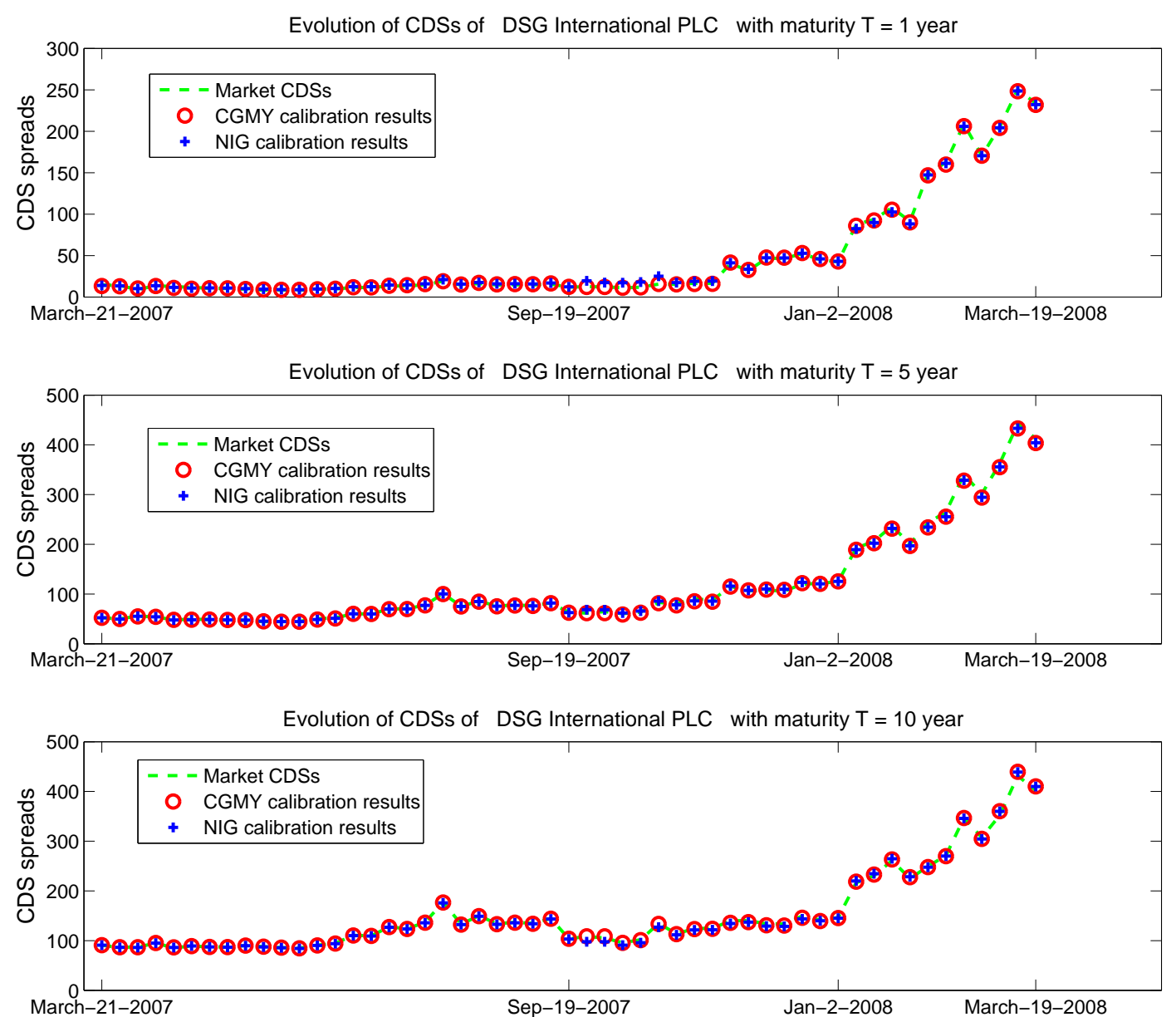

Figure 6: Calibration fit to DSG International PLC CDS spreads for the CGMY and the NIG-BM models. Market CDS spreads '- -', CGMY CDS spreads 'o', and NIG-BM CDS spreads '+'.

calibration, a value of $N=2^{10}$ is usually sufficient for the NIG-BM model, see for example Table 3 .

It is worth mentioning that the calibrated $Y$ values in CGMY often approach their upper limit, $Y=2$. Whereas this gives rise to significant convergence difficulties for various numerical methods, it is not a problem for the COS method. In fact, since larger values of $Y$ decrease the densities' peakedness, the COS method converges slightly faster, compared to lower values of $Y$, as explained in [9].

From a numerical point of view, we would like to point out that for smooth density functions we need fewer terms in the Fourier-cosine expansion than for highly-peaked functions. As a result, the number of the cosine series terms $(N)$ can be kept relatively small.

\subsection{Default Probability Term Structure}

It is interesting see how the default probability term structure generated by the models look like. In Figure 9, we give an example of the term structure for DSG International PLC under the NIG-BM model. As expected 

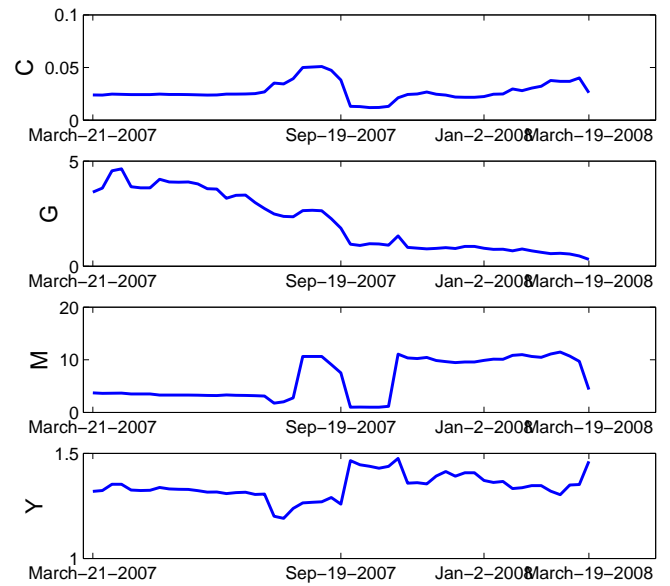
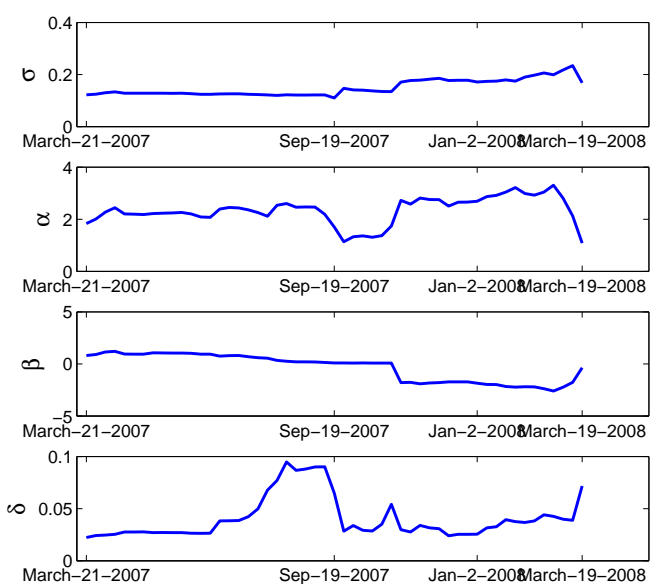

Figure 7: Evolution of the parameters of the CGMY and NIG-BM densities, respectively, for ABN AMRO.

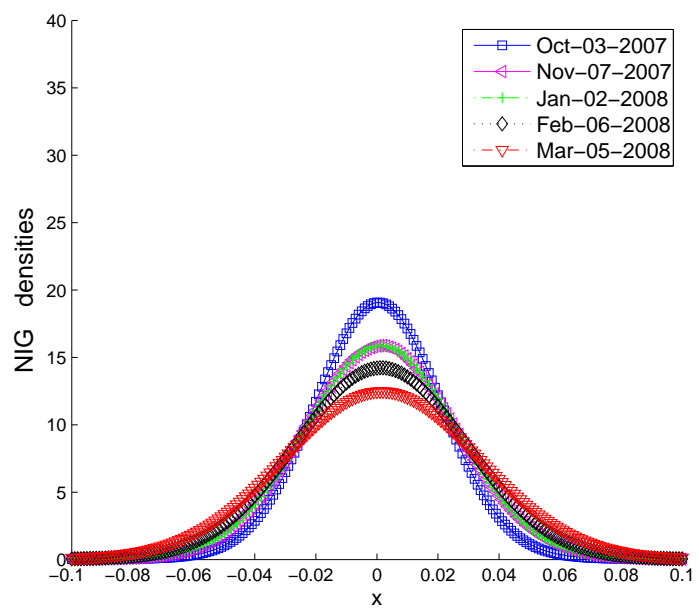

Figure 8: Evolution of the NIG-BM density for ABN AMRO.

Table 3: CPU times in computing 1-, 3-, 5-, 7- and 10-year CDSs with the COS method; Parameters are given in Table 1 and reference values are obtained by $N=2^{13}$.

\begin{tabular}{|c|c|c|c|c|}
\hline & $N$ & $2^{9}$ & $2^{10}$ & $2^{11}$ \\
\hline \multirow{2}{*}{ NIG-BM } & CPU times (sec.) & 0.121 & 0.218 & 0.418 \\
& max. abs. err. in bp. & 0.28 & $7.93 \mathrm{e}-03$ & $7.32 \mathrm{e}-06$ \\
\hline \multirow{2}{*}{ CGMY } & CPU times (sec.) & 0.122 & 0.220 & 0.423 \\
& max. abs. err. in bp. & 6.89 & 1.07 & $2.94 \mathrm{e}-02$ \\
\hline
\end{tabular}

the evolution of the default probability term structure resembles closely the evolution of the CDS spreads in Figure 6, that is, the CDS spreads increase over time, which is reflected in higher default probabilities. The CGMY model gives a similar default probability term structure. 


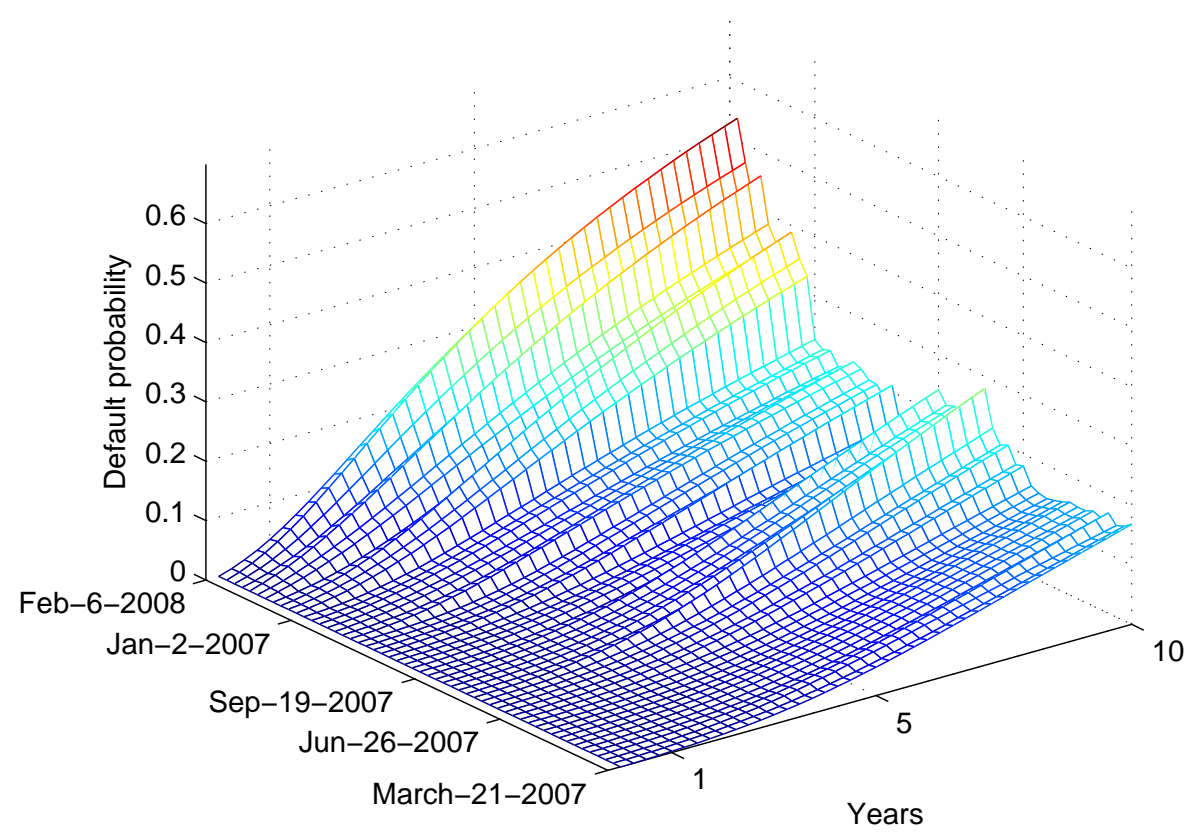

Figure 9: Default probability term structure of DSG International PLC under the NIG-BM model given by calibrating the model to the CDS weekly quotes from March 21, 2007 to February 6, 2008.

\section{Conclusion}

In this paper we introduced an efficient and flexible numerical method, called the COS method, for calculating survival/default probabilities for pricing single name Credit Default Swaps.

We take a structural approach where the firm's value is modeled by an exponential Lévy process, focusing on two well known Lévy models: the NIG-BM (a NIG model extended with a Brownian Motion) model and the CGMY model.

The main idea is to relate the credit default spreads to a series of survival/default probabilities with different maturities, and to exploit the relationship between these survival probabilities and the price of Binary Down-and-Out Barrier options. To rapidly evaluate these option prices, and thus, the survival probabilities, we generalized the option pricing method based on the Fourier-cosine series expansion of the underlying density introduced in [9, 10]. In less than half a second, the 1-, 3-, 5, 7- and 10-year default probabilities were computed with very satisfactory accuracy. We also checked the convergence of survival probabilities w.r.t. the number of monitoring dates.

The method's potential was demonstrated via calibration of the NIG-BM and the CGMY Lévy models on the quotes of the constituents of the iTraxx Series 7 and Series 8. Both models give very good fit to the market quotes. The average Root Mean Square Error is less than 1.0 basis point for both Lévy models with respect to the Series 7 data, and is less than 2.0 basis points with respect to the Series 8 data. We have presented in the paper the evolution of the CDS market quotes and the related model prices over the year covered by the two iTraxx series. What can be seen is that the models and the method manage to reproduce the market prices of CDSs even at those times when there are dramatic changes in the prices. The evolution of the model parameters, resulting from the calibration, show reasonable behavior, staying quite stable over 
time unless there are large changes in the market CDS spreads. The default probability term structures extracted from the market quotes mirror the change of the market CDS spreads over time.

From a numerical point-of-view, we saw that in many experiments we could use a smaller number of cosine series terms for the NIG-BM model than for the CGMY model as the former has a smoother density due to the diffusion part, making the COS method to converge faster.

\section{Acknowledgments}

The research presented in the paper was done while H. Jönsson was an EU-Marie Curie Intra-European Fellow with funding from the European Community's Sixth Framework Programme (MEIF-CT-2006-041115).

\section{References}

[1] Barndorff-Nielsen, O. E. (1998) Process of Normal Inverse Gaussian Type, Finance and Stochastics, 2: 41-68.

[2] Bertoin, J. (1996) Lévy Processes, Cambridge Tracts in Mathematics 121, Cambridge University Press, Cambridge.

[3] Black, F., and Cox, J. (1976) Valuing corporate securities: some effects on bond indenture provisions, The Journal of Finance, 31: 351-367.

[4] Boyarchenko, S.I. and Levendorskiü, S.Z., Non-Gaussian Merton-Black-Scholes theory, Vol. 9 Advanced Series on Statist. Science \& Appl. Probability., World Scient. Publ. Co. Inc., River Edge, NJ, 2002.

[5] Cariboni, J. (2007) Credit Derivatives Pricing under Lévy Models, PhD Thesis, K.U.Leuven, Leuven, Belgium.

[6] Cariboni, J., and Schoutens, W. (2007) Pricing Credit Default Swaps under Lévy Models, The Journal of Computational Finance, 10(4): 1-21.

[7] Carr P., Geman H., Madan D.B. and Yor M. (2002) The Fine Structure of Asset Returns: An Empirical Investigation, The Journal of Business 75(2).

[8] Cont, R., and Tankov, P. (2006) Retrieving Lévy Processes from Option Prices: Regularization of an Ill-posed Inverse Problem, SIAM Journal on Optimization, 45(1): 1-25.

[9] Fang, F. and Oosterlee, C.W. (2008a) A Novel Method For European Options Based On Fourier-Cosine Series Expansions, SIAM Journal on Scientific Computing, 31(2): 826-848.

[10] Fang, F. and Oosterlee, C.W. (2008b) Pricing Early-Exercise and Discrete Barrier Options By FourierCosine Series Expansions, working paper, submitted for publication.

[11] Hirsa, A., and Madan, D.B. (2004) Pricing American options under variance gamma. The Journal of Computational Finance, 7(2): 63-80.

[12] Jönsson, H., and Schoutens, W. (2009a) Single Name Credit Default Swaptions Meet Single Sided Jump Models. Review of Derivatives Research, 11(1-2): 153-169. 
[13] Jönsson, H., and Schoutens, W. (2009b) Pricing Constant Maturity Credit Default Swaps Under Jump Dynamics. The Journal of Credit Risk, 5(1): 1-21.

[14] Kou, S. G. (2003) On Pricing of Discrete Barrier Options. Statistica Sinica 13: 955-964.

[15] Kou, S. G., and Wang, H. (2003) First Passage Times of a Jump Diffusion Process. Advances in Applied Probability 35: 504-531.

[16] Kou, S. G., and Wang, H. (2004) Options Pricing under a Double Exponential Jump-diffusion Model. Management Science 50: 1178-1192.

[17] Lipton, A. (2002) Assets With Jumps. Risk September: 149-153.

[18] Madan, D. B., and Schoutens, W. (2007) Break on Through to the Single Side. The Journal of Credit Risk 4(3): 3-20.

[19] Madan, D. B., Carr, P. and Chang, E. C. (1998) The Variance Gamma Process and Option Pricing. European Finance Review 2: 79-105.

[20] Sato, K. (2000) Lévy Processes and Infinitely Divisible Distributions. Cambridge Studies in Advanced Mathematics 68, Cambridge University Press, Cambridge.

[21] Schoutens, W. (2003) Lévy Processes in Finance: Pricing Financial Derivatives, Wiley. 


\section{A RMSE Results of All Companies of iTraxx}

Table 4: RMSE in basis points of the computed CDSs to market CDSs (part 1)

\begin{tabular}{|c|c|c|c|c|}
\hline \multirow{2}{*}{ company name } & \multicolumn{2}{|c|}{ RMSE in S7 } & \multicolumn{2}{|c|}{ RMSE in $\mathrm{S} 8$} \\
\hline & NIG-BM & CGMY & NIG-BM & CGMY \\
\hline ABN AMRO Bank NV & 0.61 & 0.55 & 1.33 & 1.60 \\
\hline Aegon NV & 0.92 & 0.81 & 2.34 & 2.18 \\
\hline Allianz SE & 0.76 & 0.71 & 0.89 & 1.13 \\
\hline Assicurazione Generali SPA & 0.51 & 0.43 & 0.77 & 0.84 \\
\hline Aviva PLC & 0.58 & 0.51 & 1.94 & 2.08 \\
\hline AXA & 0.79 & 0.65 & 1.35 & 1.49 \\
\hline Banca Monte dei Paschi di Siena SPA & 0.65 & 0.71 & 1.62 & 1.82 \\
\hline Banco Bilbao Vizcaya Argentaria SA & 0.60 & 0.46 & 1.49 & 1.46 \\
\hline Banco Espirito Santo SA & 0.70 & 0.66 & 1.09 & 1.23 \\
\hline Banco Santander Central Hispano SA & 0.70 & 0.64 & 1.17 & 1.34 \\
\hline Barclays Bank PLC & 0.48 & 0.46 & 1.22 & 1.32 \\
\hline BNP Paribas & 0.38 & 0.30 & 1.04 & 1.07 \\
\hline Capitalia SPA & 1.29 & 1.35 & 1.44 & 2.07 \\
\hline Commerzbank AG & 0.84 & 0.62 & 1.06 & 1.13 \\
\hline Deutsche Bank AG & 0.89 & 0.77 & 1.21 & 1.30 \\
\hline Hannover Rueckversicherung AG & 0.61 & 0.62 & 1.59 & 1.61 \\
\hline Intesa Sanpaolo & 0.40 & 0.44 & 0.27 & 0.46 \\
\hline Muenchener Rueckversicherung AG & 0.59 & 0.71 & 0.99 & 0.95 \\
\hline Swiss Reinsurance Company & 1.00 & 0.87 & 2.70 & 2.38 \\
\hline Unicredito Italiano SPA & 0.57 & 0.53 & 1.33 & 1.63 \\
\hline Bayerische Motorenwerke AG & 0.54 & 0.55 & 0.95 & 1.30 \\
\hline Compagnie Financiere Michelin & 0.83 & 0.97 & 3.67 & 2.02 \\
\hline Continental AG & 1.63 & 1.10 & 1.44 & 1.54 \\
\hline DaimlerChrysler AG & 0.76 & 0.75 & 1.10 & 1.12 \\
\hline GKN Holdings PLC & 2.19 & 1.50 & 2.53 & 2.17 \\
\hline Peugeot SA & 0.74 & 0.64 & 1.72 & 2.28 \\
\hline Renault & 0.80 & 0.64 & 2.73 & 2.56 \\
\hline Valeo & 1.32 & 1.01 & 1.67 & 1.43 \\
\hline Volkswagen AG & 0.78 & 0.82 & 2.86 & 1.67 \\
\hline Accor & 0.83 & 0.89 & 2.57 & 2.07 \\
\hline Aktiebolaget Electrolux & 0.69 & 0.35 & 1.79 & 2.20 \\
\hline Altadis SA & 1.83 & 1.45 & 1.60 & 1.51 \\
\hline British American Tobacco PLC & 0.67 & 0.29 & 1.55 & 1.60 \\
\hline Cadbury Schweppes PLC & 0.62 & 0.55 & 1.60 & 1.59 \\
\hline Carrefour & 0.71 & 0.68 & 1.35 & 0.90 \\
\hline Compass Group PLC & 0.78 & 0.66 & 1.55 & 0.99 \\
\hline Deutsche Lufthansa AG & 0.89 & 0.68 & 1.61 & 1.83 \\
\hline Diageo PLC & 0.32 & 0.32 & 1.49 & 1.16 \\
\hline DSG International PLC & 0.93 & 0.72 & 4.27 & 3.33 \\
\hline Gallaher Group PLC & 0.41 & 0.52 & 1.07 & 0.57 \\
\hline Groupe Auchan & 0.44 & 0.46 & 1.51 & 0.90 \\
\hline Experian Finance PLC & 0.71 & 0.52 & 1.82 & 1.70 \\
\hline Henkel KGaA & 0.74 & 0.73 & 1.57 & 1.32 \\
\hline Kingfisher PLC & 1.17 & 0.70 & 3.58 & 3.30 \\
\hline Koninklijke Philips Electronics NV & 0.81 & 0.69 & 1.40 & 1.47 \\
\hline
\end{tabular}


Table 5: RMSE in basis points of the computed CDSs to market CDSs (part 2)

\begin{tabular}{|c|c|c|c|c|}
\hline \multirow{2}{*}{ company name } & \multicolumn{2}{|c|}{ RMSE in S7 } & \multicolumn{2}{|c|}{ RMSE in $\mathrm{S} 8$} \\
\hline & NIG-BM & CGMY & NIG-BM & CGMY \\
\hline LVMH Moet Henessy Louis Vuitton & 0.62 & 0.72 & 1.47 & 1.17 \\
\hline Marks and Spencer & 1.15 & 0.89 & 1.76 & 2.22 \\
\hline Metro AG & 0.52 & 0.60 & 1.10 & 1.18 \\
\hline PPR & 1.48 & 0.78 & 1.92 & 1.97 \\
\hline Safeway Ltd & 1.09 & 0.94 & 1.72 & 1.49 \\
\hline Sodexho Alliance & 0.46 & 0.42 & 1.19 & 1.32 \\
\hline Svenska Cellulosa Aktiebolaget SCA & 0.52 & 0.40 & 1.69 & 1.73 \\
\hline Tate \& Lyle PLC & 0.66 & 0.94 & 0.94 & 1.01 \\
\hline Tesco PLC & 0.33 & 0.44 & 1.28 & 0.77 \\
\hline Unilever NV & 0.52 & 0.48 & 1.50 & 0.51 \\
\hline Centrica PLC & 0.80 & 1.15 & 2.14 & 1.23 \\
\hline Edison SPA & 0.40 & 0.58 & 0.88 & 0.74 \\
\hline Enel SPA & 0.76 & 0.75 & 2.96 & 3.00 \\
\hline Energie Baden-Wuerttemberg AG & 0.46 & 0.52 & 1.60 & 0.99 \\
\hline Fortum Oyj & 0.59 & 0.63 & 1.70 & 0.98 \\
\hline Gas Natural SDG SA & 0.32 & 0.45 & 1.87 & 1.54 \\
\hline GAZ de France & 0.25 & 0.41 & 1.43 & 1.00 \\
\hline Iberdrola SA & 0.71 & 1.97 & 1.66 & 1.54 \\
\hline National Grid PLC & 1.25 & 0.99 & 1.69 & 1.10 \\
\hline Repsol YPF SA & 1.06 & 1.00 & 1.36 & 1.30 \\
\hline RWE AG & 0.22 & 0.41 & 0.89 & 0.60 \\
\hline SUEZ & 0.46 & 0.52 & 0.94 & 0.76 \\
\hline Union Fenosa SA & 0.59 & 0.64 & 2.11 & 1.85 \\
\hline United Utilities PLC & 0.32 & 0.90 & 0.97 & 0.88 \\
\hline Vattenfall Aktiebolag & 0.36 & 0.52 & 1.25 & 0.80 \\
\hline Veolia Environnement & 1.55 & 0.97 & 1.19 & 1.19 \\
\hline Adecco SA & 0.63 & 0.31 & 1.71 & 2.06 \\
\hline Akzo Nobel NV & 0.67 & 0.55 & 1.67 & 1.28 \\
\hline Arcelor Finance & 0.66 & 0.38 & 1.71 & 1.96 \\
\hline Bayer AG & 0.57 & 1.02 & 1.42 & 1.25 \\
\hline Ciba Specialty Chemicals Holding Inc. & 1.71 & 0.74 & 1.96 & 2.26 \\
\hline Compagnie de Saint-Gobain & 0.77 & 0.51 & 2.14 & 1.68 \\
\hline European Aeronautic Defence and Space Company EADS NV & 0.65 & 0.45 & 1.42 & 1.03 \\
\hline Glencore International AG & 2.29 & 1.17 & 2.55 & 3.52 \\
\hline Imperial Chemical Industries PLC & 0.94 & 0.54 & 0.74 & 0.70 \\
\hline Koninklijke DSM NV & 0.97 & 0.37 & 1.45 & 1.51 \\
\hline Lafarge & 1.40 & 1.04 & 1.77 & 1.89 \\
\hline Linde AG & 0.94 & 0.91 & 1.13 & 1.40 \\
\hline Sanofi-Aventis & 0.45 & 0.45 & 1.16 & 0.83 \\
\hline Siemens AG & 0.74 & 1.40 & 1.21 & 1.05 \\
\hline Solvay & 0.48 & 1.27 & 0.95 & 1.04 \\
\hline ThyssenKrupp AG & 1.53 & 0.84 & 2.23 & 2.08 \\
\hline UPM-Kymmene Oyj & 1.31 & 1.06 & 3.06 & 2.99 \\
\hline VINCI & 0.76 & 0.49 & 1.28 & 1.21 \\
\hline Bertelsmann AG & 1.33 & 1.90 & 1.36 & 1.10 \\
\hline
\end{tabular}


Table 6: RMSE in basis points of the computed CDSs to market CDSs (part 3)

\begin{tabular}{|c||c|c||c|c|}
\hline \multicolumn{1}{|c||}{ company name } & \multicolumn{2}{c||}{ RMSE in S7 } & \multicolumn{2}{c|}{ RMSE in S8 } \\
\cline { 2 - 5 } & NIG-BM & CGMY & NIG-BM & CGMY \\
\hline British Telecommunications PLC & 1.56 & 1.20 & 1.62 & 1.65 \\
Deutsche Telekom AG & 1.16 & 1.24 & 2.19 & 1.51 \\
France Telecom & 1.31 & 1.77 & 1.48 & 1.38 \\
Hellenic Telecommunications Organisation SA & 1.44 & 1.05 & 3.54 & 2.79 \\
Koninklijke KPN NV & 2.29 & 0.64 & 1.90 & 3.17 \\
Pearson PLC & 1.80 & 0.81 & 1.68 & 1.43 \\
Reuters Group PLC & 0.87 & 1.15 & 1.12 & 1.04 \\
STMicroelectronics NV & 0.80 & 0.87 & 0.97 & 1.79 \\
Telecom Italia SPA & 1.82 & 1.58 & 2.55 & 2.46 \\
Telefonica SA & 1.20 & 0.96 & 1.59 & 1.59 \\
Telekom Austria Aktiengesellschaft & 0.99 & 0.77 & 1.59 & 1.27 \\
Telenor ASA & 0.57 & 0.90 & 0.85 & 0.93 \\
TeliaSonera Aktiebolag & 1.05 & 0.70 & 1.61 & 1.23 \\
Vivendi & 2.02 & 1.58 & 2.37 & 2.64 \\
Vodafone Group PLC & 1.27 & 1.94 & 2.02 & 1.69 \\
Wolters Kluwer NV & 1.51 & 1.43 & 1.45 & 1.19 \\
\hline
\end{tabular}

